\title{
DocUmentos
}

\section{Creer en la Independencia. El catecismo o Instrucción popular de Juan Fernández de Sotomayor}

\author{
Patricia Cardona Zuluaga ${ }^{1}$ \\ Universidad EAFIT (Colombia)
}

\begin{abstract}
Nosotros hemos entendido que se ha tomado como pretesto para seducir a los sencillos, la santa religión del crucificado, se les ha hecho creer que se pretende su ruina y que se persigue a los verdaderos cristianos.
\end{abstract}

Juan Fernández de Sotomayor y Picón, Bogotá, 13 de agosto de $1830^{2}$

La enseñanza catequística fue desde la antigüedad un medio eficaz en la inculcación de los preceptos indispensables para la vida del buen cristiano; coincidía esa práctica con varias características de las sociedades teocéntricas en las que la lectura y la escritura no eran ejercicios dominantes y la posesión de un manuscrito era una rareza. A través del catecismo se sintetizaban aspectos sustantivos de las creencias religiosas, de modo que pudieran ser fácilmente aprendidos por los feligreses. Al valerse de la palabra enunciada oralmente en espacios públicos, se aseguraba que pocos ministros indoctrinaran a muchos creyentes. A través de una estructura simple basada en preguntas y respuestas

\footnotetext{
${ }^{1}$ (azuluaga@eafit.edu.co) Historiadora, Magíster en Historia, Doctora en Historia (Universidad de los Andes, Bogotá-Colombia). Profesora Titular del Departamento de Humanidades de la Universidad Eafit (Medellín-Colombia). Miembro del grupo de Investigación Estudios sobre Filosofía, Hermenéutica y Narrativas de la misma universidad. Este texto se deriva de la Investigación sobre las relaciones entre escritura histórica y retórica en el siglo XIX colombiano que en la actualidad adelanta con el apoyo de la Universidad EAFIT.

${ }_{2}^{2}$ Biblioteca Luis Ángel Arango (Blaa) Nos el Doctor Juan Fernández de Sotomayor, provisor y vicario jeneral jeneral y gobernador del arzobispado por el Ilustrísimo Señor Doctor Fernando Caicedo, dignísimo arzobispo en su pastoral visita, 1830, en http://www.banrepcultural.org/sites/ default/files/92570/brblaa760193.pdf. Ingreso, Julio 7 de 2015
} 
formuladas de antemano, la catequesis fijaba en la memoria las verdades inalterables de la fe para ser repetidas verbalmente, conservando el orden y la secuencia aprendidas. El catecismo fue una herramienta ineludible en la propagación de creencias religiosas, no sujetas a dudas ni a razonamientos críticos o reflexivos, su finalidad no era precisamente la de conformar un pensamiento crítico, sino la de ejercitar la memoria como facultad del aprendizaje y grabar en ella preceptos incuestionables y centrales para la vida en sociedad, por ello mismo inalterables en su forma y en su contenido.

La larga tradición catequística, así como su raigambre en la sociedad, fueron factores decisivos para que las incipientes imprentas hicieran uso de esta forma de organización del discurso y la convirtieran en impreso popular, cuya destinación fundamental, además de enseñar principios religiosos, era la de poner a disposición del "vulgo" distintos conocimientos concebidos como verdades incuestionables emanadas de una autoridad. En el siglo XVII la Reforma y la Contrarreforma también se valieron del catecismo, tanto impreso como verbal, para propagar sus respectivos principios; Martín Lutero (14831546) y Juan Calvino (1509-1564), compusieron y dieron a la estampa sendos catecismos que enseñaban los dogmas fundamentales de la Iglesia reformada y su distanciamiento de la autoridad pontificia romana. La Contrarreforma Católica, a través del concilio de Trento (1545-1563), auspició la impresión de catecismos que ayudaran a combatir los avances reformadores y que, al tiempo, difundieran una sola visión de la fe y de la Iglesia³.

La política también se apoyó en los catecismos; Erasmo de Rotterdam, uno de los más importantes intelectuales cristianos del Renacimiento, imprimió un catecismo para enseñar a los príncipes las reglas del decoro y control del cuerpo ${ }^{4}$, base de los famosos manuales de urbanidad destinados a contener la violencia y gracias a los cuales se puede explicar, en parte, el proceso monopolización de la violencia por parte del Estado, así como el de la civilización.

Así pues, el catecismo como una forma culturalmente reconocible y comprensible en la cultura occidental, estuvo casi siempre ligado a la religión y a una estructura de pensamiento que fundaba el conocimiento en la nemotecnia. No se trata de cualquier conocimiento, los catecismos enseñaban verdades

${ }^{3}$ A partir del Concilio de Trento se escribieron dos catecismos de gran influencia en el Occidente católico; nos referimos al catecismo de Gerónimo Ripalda (1536-1638): Doctrina Christiana con una exposición breve compuesta por el maestro Hieronymo de Ripalda de la Compañía de Jesús (con Licencia. En Burgos, por Philippe de Iunta, 1591 abiertamente anti protestante), y al de Gaspar Astete (1537-1601): Institución y guía de la juventud christiana, primera parte. Donde se trata como han de enseñar los padres a los hijos a ser obedientes y temerosos de Dios, y las virtudes principales que ha de tener el mancebo christiano. Por el P. Gaspar Astete de la Compañía de Jesús. Con privilegio. En Burgos, casa de Philippe Iunta, 1592, menos polémico y combativo, y de más fácil asimilación. Ambos textos gozaron de gran importancia en Hispanomérica y además de evangelizar, sirvieron para enseñar español, lectura y moral.

${ }^{4}$ De Civilitate morum puerilium per D. Erasmus Roterodamum libelus ab autore recognitus, Antverpiae Apvd Guillielmum Vorstermannum Anno MDXXXIII. 
irrefutables provenientes de una autoridad, como bien lo expresaba la lógica "seguimos la autoridad cuando nos confiamos en los dichos de otros, y este conocimiento se llama fe"s.

Los catecismos no se fundaban en la originalidad o en la búsqueda de un saber nuevo, sino en la reiteración de lo ya conocido o de aquello tenido por "verdadero" y susceptible de ser grabado en la memoria de todos, se componían para ser recitados en voz alta entre un nutrido grupo de oyentes que debían ir fijando en la memoria los contenidos, según el estilo y el orden en el que eran enunciados.

\section{Catecismos patrióticos}

Con la Ilustración y el auge del pensamiento ilustrado tampoco decayó la forma catequística, de hecho, fue utilizada como una herramienta efectiva en la instrucción popular, para inculcar los principios políticos emergentes que derribaban el orden teocéntrico conocido y alzaban, sobre sus ruinas, el edificio político de la democracia, la libertad y la soberanía popular. Así pues, el orden en ciernes necesitó de veteranas formas en las cuales verter sus contenidos, a fin de lograr impacto entre pobladores convencidos de que el orden y la jerarquía como designio divino eran inalterable so pena de ser castigados por dios y por sus emisarios. En este contexto, los catecismos fueron vehículos básicos para la difusión de los nuevos lenguajes políticos y filosóficos y de los proyectos políticos que ellos encarnaban, ayudaron a emplazar un lenguaje patriótico que revertía el orden de los términos, ya que ahora el objeto de la devoción y el posible martirio no era la religión sino la recién fundada patria, tierra amada y venerada en procura de cuya libertad y felicidad eran insuficientes todos los sacrificios de sus hijos ${ }^{6}$.

Tal es el caso del documento que transcribimos para este número de la revista, un Catecismo político cuya finalidad era convencer a todos sus "lectores" de que el reclamo por la Independencia del Nuevo Reino de Granada, además de necesario, era justo. Escrito por Juan Fernández de Sotomayor, cura de la parroquia de Mompóx en la Costa Atlántica Colombiana, el Catecismo político o Instrucción popular ${ }^{7}$ resumía puntos relevantes del pensamiento

\footnotetext{
${ }^{5}$ Biblioteca Nacional de Colombia (BNC), Fondo Pineda 177. Pieza 3. Lecciones de Lójica para el curso de filosofía del Colegio mayor Seminario de San Bartolomé en el año de 1822. Por el D. F. R. Bogotá, Imprenta de Espinosa, año de 1823, p. 17.

${ }^{6}$ En este momento primaba el concepto de patria y el de nación apenas empezaba a cargarse de su acepción moderna. La idea de patria reforzaba la relación con el terruño de origen y con los deberes que debía asumir el patriota en su defensa. La idea de patria convierte a todo ciudadano en un potencial soldado de su causa, para ello apela a la pasión antes que a la razón.

${ }^{7}$ Catecismo o instrucción popular por el C. Dr. Juan Fernández de Sotomayor, Cura rector y Juez Eclesiástico de la valerosa Ciudad de Mompóx, Cartajena de Indias, por el Cura Manuel González y Pujól, 1814. La transcripción la hacemos de la reimpresión de 1820: BNC, Fondo Quijano 426, 
independentista posterior a los sucesos de la Corte de Cádiz (1808), a las Juntas de Gobierno y los cambios en las solicitudes de las insurrecciones que en principio (hacia 1810) reclamaban la autonomía y que luego (hacia 1814), demandaban la independencia y la soberanía absoluta como un derecho incuestionable después de años de opresión y vejaciones por parte de España. No se trata de un opúsculo escrito para el conocimiento de todo el virreinato; la finalidad del catecismo era respaldar la Independencia declarada por Mompóx el 6 de agosto de 1810, y de paso minimizar la influencia del clero realista que predicaba en contra de tales eventos en las comarcas vecinas. Sin embargo, el catecismo trascendió las sabanas costeras y en 1820, después de finalizada la contienda entre España y la Nueva Granada, y en plena constitución de la República de Colombia, vio la luz una reimpresión que es la que hemos transcrito aquí.

Juan Fernández de Sotomayor nació en 1777 en Cartagena y estudió en el Colegio de San Bartolomé y en el Colegio mayor de Nuestra Señora del Rosario, prestigiosos centros educativos donde se formaban las elites del virreinato de la Nueva Granada. Aparte de los consabidos conocimientos teológicos, Fernández de Sotomayor estudió a los teóricos del derecho de gentes español, como Francisco de Vitoria y Francisco Suárez entre otros. Recibió los influjos del pensamiento ilustrado francés en boga en esos momentos en el virreinato. Asistió a los cursos de Camilo Torres y Tenorio (1766-1816), uno de los pensadores más importantes de la generación de la Independencia, y quien fuera el redactor del famoso Memorial de Agravios, texto que invoca la igualdad de los españoles americanos y los españoles peninsulares y formula la teoría de la soberanía popular como fundamento de la patria ${ }^{8}$.

En un momento de plena actividad bélica de la Independencia, Juan Fernández decidió escribir su catecismo para combatir las avanzadas de los enemigos de este movimiento, ya que en la Costa Atlántica colombiana varios curas afectos a los españoles enarbolaron una lucha sin cuartel a través de los púlpitos para persuadir a sus feligreses de apoyar a los insurrectos ${ }^{9}$. Pero más allá de contrarrestar a los detractores de la Independencia, Juan Fernández se proponía instruir a la mayor cantidad de gente posible, a través de un texto sencillo, que pudiera recitarse en diversos auditorios y que, sobre todo, llegara a los oídos de aquellos menos capacitados para leer y comprender sesudas

Catecismo o Instrucción popular, Cura Rector y Juez Eclesiástico de la valerosa ciudad de Mompox, en la imprenta de C. B. E., 1820. La misma edición puede consultarse en la colección digital de la Biblioteca Luis Ángel Arango: http://admin.banrepcultural.org/sites/default/files/92260/BN MG_6080-catecismo-o-instruccion-popular-1820.pdf, ingreso julio 7 de 2015.

${ }^{8}$ La historiografía colombiana lo llamó Memorial de Agravios, pero su nombre real es: Representación del muy ilustre cabildo de Santafé a la Suprema Junta Central de España, redactado en 1809, solamente fue publicado en 1832.

${ }_{9}$ Ocampo López, Javier, El Cura Juan Fernández de Sotomayor y Picón y los catecismos de la Independencia, Bogotá, Universidad del Rosario, 2010. 
teorías, las mismas que puestas bajo la forma del catecismo y en un lenguaje simple, se impregnaban de un tono de autoridad y "verdad" emanado de una instancia superior a la regia o clerical, confiriéndole a esas teorías un aire metafísico que las hermanaba casi con la fe. En otros términos, al ser llevadas a la forma del catecismo, las teorías políticas que pregonaba su autor adquirían un cariz "religioso", para creer más que para pensar ${ }^{10}$, y para persuadir conforme la retórica, lo cual significaba "determinar la voluntad a que actúe en consecuencia"11.

Es probable que, además de la tradición catequística que bien debía conocer Fernández de Sotomayor, también hallara su inspiración en un pequeño texto que circuló en España desde 1809 con el propósito de instruir al pueblo contra la tiranía francesa, Instrucción popular en forma de catecismos sobre la presente guerra ${ }^{12}$, en el prólogo su autor conminaba a todos los eclesiásticos a instruir "por escrito y de palabra, en sermones, en conversaciones"13, al pueblo y al ejército contra el tirano. Es de notar que a través de estos textos algunos miembros del clero asumieron una significación pública como delatores de la injusticia y educadores del pueblo en contra de la tiranía y el despotismo.

Fernández de Sotomayor fue un clérigo que asumió la defensa de la patria como una deber consustancial a su ministerio y exhortaba al clero a redoblar esfuerzos en la instrucción popular para no volver "jamás a la dependencia antigua"14. Para conseguirlo era indispensable tener el apoyo irrestricto de la mayor parte de la población a la que aspiraba llegar a través de su pequeño texto. El éxito del catecismo en términos de penetración cultural quedó evidenciado en la campaña que contra él y contra su autor desató la Inquisición de Cartagena por considerarlo subversivo contra la monarquía española y en que fuera el precursor de otros catecismos que circularon en Nueva Granada y en Colombia a lo largo del siglo XIX ${ }^{15}$.

10 "no debe buscarse la evidencia, ni pedirse la razón intrínseca de aquellas cosas que se proponen para creer. El objeto de la fe siempre es obscuro y no puede componerse con la evidencia", BNC, Fondo Pineda 177, pieza 3. Lecciones de Lójica, op. cit., p. 17.

${ }^{11}$ Gómez Hermosilla, Josef. El arte de hablar en prosa y en verso. Madrid, Imprenta del Real, Tomo 2, 1826, p. 26.

${ }^{12}$ Instrucción popular en forma de catecismos sobre la presente guerra. La consagra al exercito y al pueblo de España, un presbítero, Sevilla, en la Imprenta del Real, 1809.

13 Ibid.

${ }^{14}$ BNC, Fondo Quijano 426, Catecismo o instrucción popular por el C. Dr. Juan Fernández de Sotomayor, op. cit., p. 13.

15 A lo largo del siglo XIX circularon en Colombia varios catecismos políticos, veáse: Catecismo político arreglado a la constitución de la República de Colombia de 30 de agosto de 1821. Para el uso de las escuelas de primeras letras del Departamento de Orinoco. Dispuesto por el Licenciado José de Grau, asesor de la intendencia del mismo departamento y dedicado a la juventud cumanesa, año de 1822. Impreso por orden del supremo gobierno para el uso de las escuelas de Colombia, Bogotá, Imprenta de Nicomedes Lora, 1824, Catecismo republicano para la Instrucción Popular. Redactado a escitación del ciudadano presidente Manuel Murillo Toro, destinándolo con especialidad a las escuelas de Guardias colombianas, creadas por el decreto presidencia del $1^{\circ}$ de setiembre de 1861, por Cerbeleón Pinzón, Bogotá, Imprenta de El Mosaico, 1864. 
Asimismo, es preciso señalar que el catecismo de Fernández no es una pieza aislada, ya veíamos una referencia similar e importante en España; en el continente americano los catecismos patrióticos fueron una vía importante para dar a conocer y propagar el ideario independentista ${ }^{16}$, y no en vano fueron clérigos la mayor parte de los responsables de estos textos. Ello puede explicarse por varias razones; una de ellas radica en su conocimiento de la lectura y la escritura alternadas con un adiestramiento cuidadoso en la oratoria, lo que, seguramente, facilitó la composición de textos como estos que desarrollaban su mayor riqueza en la alocución pública a través de lecturas colectivas. Por otra parte, los clérigos conocían bien la estructura de los catecismos y sus inmensas potencialidades; recuérdese que ellos catequizaban y que muchos componían pequeños textos para instruir en sus parroquias, textos que se acomodaban incluso a las lenguas indígenas en las que debían predicar ${ }^{17}$. Finalmente, señalemos que la función de estos textos no era proponer nada nuevo, ni reflexionar de manera erudita sobre una teoría o un precepto. Los autores "componían", no "creaban", es decir, dedicaban sus esfuerzos a extraer de autoridades elementos fundamentales que debía aprender y memorizar todo buen cristiano, y en los albores de la Independencia todo buen patriota.

\section{Qué enseñaba el catecismo patriótico se Sotomayor y Picón}

El objeto del cura Fernández de Sotomayor no era componer un tratado sistemático sobre doctrina alguna, ni engalanar el texto con pomposas referencias compresibles para muy pocos; su objeto era presentar de la manera más esquemática, sucinta y sencilla posible algunos principios que ayudaran explicar la lucha por la independencia y, de paso, constituirlos como nuevos actores políticos en el escenario de construcción de una nueva república.

Mientras gran parte de los discursos de los precursores de la Independencia postulaban la idea de que los americanos eran tan españoles como los peninsulares, es decir, pregonaba un principio de identidad que reclamaba un trato igualitario por ser hijos de la misma madre patria, el catecismo de Sotomayor se distanciaba de esa posición al señalar que los americanos formaban parte de una nación distinta a la española. No se refiere pues a una patria en particular, sino a los americanos como suerte de conjunto homogéneo,

${ }^{16}$ Sagredo Baeza, Rafael, De la colonia a la república. Los catecismos políticos americanos, Madrid, Mapfre, Editorial Doce Calles, S.L, 2009. Es este un interesante estudio sobre los catecismos políticos que circularon en Hispanoamérica durante la Independencia.

17 Veáse por ejemplo un manuscrito para la cristianización en BNC. Fondo Cuervo 2619, pieza 4: Catecismo en el lenguaje de los indios Cunacunas traducido observando la mayor propiedad del idioma como sigue (1722), puede consultarse en el fondo digital de la Biblioteca Nacional de Colombia: http://www.bibliotecanacional.gov.co/recursos_user/fcuervo/fcuervo_2613_pza4.pdf acceso, Julio 12 de 2015. 
sometido a las vejaciones motivadas por la ambición del conquistador español.

Visto así, la conquista y la colonia no son expresiones del celo religioso español, sino una empresa de exterminio y explotación de la que también participó un clero ignorante y codicioso que sembró una fe equívoca a través del terror. Esas alusiones cumplían con el propósito demostrar que la Independencia no era contraria a la religión ni a la Iglesia, precisamente porque la evangelización se había encausado por sendas equívocas, mientras que el verdadero fervor agonizaba entre el abandono, la ignorancia y la ausencia total de libros que borraran a los feligreses la "creencia en patrañas y en falsos milagros"18.

Fernández Sotomayor fue un claro representante del clero ilustrado, muy posiblemente conoció los textos de Bartolomé de las Casas (1484-1566), Benito Jerónimo de Feijoo (1676-1764) y de Gaspar Melchor de Jovellanos (17441811). También debió leer en los periódicos que circulaban en la Nueva Granada algunas de las ideas más importantes Ilustrados franceses, como Montesquieu (1689-1755) o Rousseau (1712-1778); su defensa de la Instrucción pública como única vía para vencer la ignorancia y la apatía son evidencia irrefutable de su compromiso político. Ese compromiso quedó, pues, claramente expresado en la composición de su catecismo que, además de consignar una serie de preceptos sobre la importancia de la Independencia y el derecho que legitimaba esta lucha, intentó, a través de un lenguaje sencillo y sintético, exponer algunas de las más importantes teorías del derecho de gentes español y de la teología jurídica española del siglo XVI, en las figuras de Francisco de Vitoria (14861546), y de Francisco de Suárez (1548-1617), de donde extrajo las tres grandes tesis que vertebran el texto, ellas son:

La negación de la donación papal como título que legitimaba la posesión y conquista, en nombre de la religión, de los pueblos americanos; Fernández de Sotomayor alegó que la donación papal por parte de Pedro era meramente espiritual y que habían sido los autores españoles, en contravía de los de otras latitudes, los responsables de sostener el poder temporal del papa, en todo caso, una falacia.

La tesis de la conquista también fue denegada al señalar que no cabía ningún derecho natural del conquistador sobre el conquistado. Si ese derecho se aplicaba, entonces, la misma España era criminal al oponerse a las presiones conquistadoras de Francia que entonces padecía. En este predicamento se incluye una preocupación que atormentaba a los americanos y era si no actuaban como traidores e ingratos al abandonar a España en un momento de tan profunda crisis. La respuesta se organizó sobre la tesis de la disolución del pacto social y la reversión de la soberanía del pueblo provenientes de Francisco de Suárez.

\footnotetext{
${ }^{18}$ BNC, Fondo Quijano 426, Catecismo o instrucción popular por el C. Dr. Juan Fernández de Sotomayor, op. cit., p. 15
}

Araucaria. Revista Iberoamericana de Filosofía, Política y Humanidades, año 17, $\mathrm{n}^{\circ} 34$. Segundo semestre de 2015. Pp. 397-410. ISSN 1575-6823 e-ISSN 2340-2199 doi: 10.12795/araucaria.2015.i34.20 
La tercera tesis era la de la evangelización, que refuta Fernández de Sotomayor alegando que el móvil de la Conquista no fue en modo alguno la evangelización, sino que se trató de una empresa fraguada por la codicia y no por el celo religioso, y que, en definitiva, quienes llegaron a América fueron "gentes ignorantes, hombres criminales detenidos en las cárceles, la hez de pueblo"19.

A través de estas tesis se enarboló un discurso político que enfatizó las vejaciones y crímenes cometidos por los españoles contra los indígenas americanos. Fernández de Sotomayor denunciaba la indigna posición de la religión y de sus pastores que acompañaron la cruz de la espada para cristianizar a la fuerza a los más débiles. Estos argumentos ayudaron a configurar un relato que legitimó la lucha Independentista como una guerra "acaso la más justa y santa que se ha visto en el mundo de muchos siglos acá" 20 , y seguramente estuvieron en la base de los relatos patrióticos que exaltaron la grandiosidad de las justas de Independencia y la perfidia de los opositores españoles. Relatos estereotipados que no responden en sentido estricto a la verdad, pero que constituyen el bastión del pasado que da sentido a la existencia política de la patria y traza para los ciudadanos un glorioso porvenir, anunciado ya por la magnificencia épica de sus héroes, de sus luchas y de sus victorias.

A lo largo de su vida, Fernández de Sotomayor siguió defendiendo la causa patriótica y participando activamente de las distintas instancias políticas que ayudaron a fundar la república, fue representante de la provincia de Cartagena en el Congreso de las provincias Unidas (1816), Representante en el Consejo de la Gran Colombia (1822-1826), Representante en la Convención de Ocaña, (1828) y de la Convención Granadina (1832). Además de cura Párroco de Mompóx (184-1815 y 1821-1822), fue Canónigo Doctoral de la catedral de Bogotá y Vicario General de ese arzobispado. En él no decayó la convicción de que la educación popular era una vía ineluctable para combatir el atraso y la ignorancia que "serán siempre el azote más cruel de la misma sociedad" 21 . En sus sermones y pastorales siempre incluía la instrucción mediante el catecismo como una obligación del clero en todas las parroquias. El catecismo no debía confundirse con la predicación y el sermón, era una actividad distinta que requería de tiempo y dedicación para explicar por medio de palabras fáciles y sencillas "a quienes nada aprovecharían una plática o un sermón"22. Juan Fernández de Sotomayor murió en Cartagena de Indias en 1849.

${ }^{19}$ BNC, Fondo Quijano 426, Catecismo o Instrucción popular por el C. Dr. Juan Fernández de Sotomayor, p. 9

${ }^{20}$ Ibid, p. 8.

${ }^{21}$ BNC. Fondo Pineda 309, pieza 27. Carta pastoral que el Ilustrísimo Señor Obispo de la Diócesis de Cartagena dirige a los venerables párrocos du fieles después de la visita general en la misma Diócesis de Cartagena. Imprenta de Ruiz por J. María Angulo, septiembre de 1838, p. 25.

22 Ibid, p. 25. 
Catecismo o instrucción popular por el C. Dr. Juan Fernández de Sotomayor. Cura rector y vicario juez eclesiástico de la valerosa ciudad de Mompóx. De orden superior. Reimpreso en la imprenta del C. B. E. Año de 1820, P. 15.

\section{Instrucción popular}

\section{Lección I.}

\section{Refútanse los fundamentos contrarios a la independencia.}

P. ¿De quién dependía la América antes de la revolución de España?

R. De sus Reyes.

P. ¿Esta sumisión o dependencia tenía algún fundamento en justicia?

R. Ninguno tuvo en su principio.

P. ¿Qué títulos se han alegado para mantener esta dependencia?

R. Tres: a saber, la donación del Papa, la Conquista y la propagación de la Religión Cristiana.

P. ¿La Donación del Papa no ha sido un título legítimo?

R. No, porque el Vicario de Jesu-Cristo no puede dar ni ceder lo que no ha sido jamás suyo, mucho menos en calidad de Papa o sucesor de San Pedro, que no tiene autoridad ni dominio temporal, y el imperio que le fue confiado al mismo San Pedro, y que ha pasado a sus legítimos sucesores ha sido puramente espiritual como se evidencia por las mismas palabras que contienen la plenitud del poder Apostólico.

P. ¿Pues qué, el Papa Alejando VI, autor de esta donación, no conocía que no tenía tal poder?

R. Bien pudo no haberlo conocido; y no es de extrañarse en aquel sitio de ignorancia en se atribuyan a los Pontífices Romanos el derecho de destronar a los mismos Reyes, nombrar a otros y absolver a los vasallos del juramento de fidelidad, como sucedió en Francia y otros reinos.

P. ¿Y puede presumirse esta misma ignorancia respecto al Rey Fernando que ocurrió al Papa por esta donación?

R. El hecho solo de ocurrir lo comprueba. Acaso ninguna Nación ha habido más ignorante que la Española en esta materia, pues que aun después de los escritos de los sabios de otros reinos sobre la autoridad pontifica y sus preciosos términos, con los fundamentos más ineluctables, los escritores españoles han sido siempre los que han sostenido el poder temporal del Papa, y hasta estos últimos tiempos es, que uno u otro ha tenido carácter y firmeza para oponerse a preocupaciones tan antiguas.

P. ¿Y la conquista no es un motivo de justicia para dominar a la América? 
R. La conquista no es otra cosa que el derecho que da la fuerza contra el débil, como el que tiene un ladrón, que con mano armada y sin otro antecedente que el de quitar lo ajeno, acomete a su legítimo dueño, que, o no se resiste, o le opone una resistencia débil. Los conquistados así como el que ha sido robado pueden y deber recordar sus derechos luego que se vean libres de la fuerza, o puedan oponerle otras superior.

P. ¿Qué derechos son estos que pueden recobrar los conquistados?

R. Los mismos que gozaban antes de la conquista; la libertad e independencia del conquistador.

P. ¿Luego la conquista no da al conquistador el menor derecho justo y legítimo?

R. Ninguno ciertamente, pues que a darles alguno sería un delito resistir sus efectos, y entonces serian entre otros muchos, unos criminales los españoles que no quieren dejarse conquistar de los franceses, y que cuando lo han sido, han tratado de resistir en el momento en que se ha visto libres de la fuerza.

P. ¿Y por qué la América no ha recobrado su libertad hasta ahora, aprovechándose de la oportunidad de ver invadida la España por Bonaparte? ¿No le será vituperada haberla desamparado en circunstancias tan críticas?

R. En cuanto a lo primero, porque la fuerza nos había tenido oprimidos: porque la ignorancia en que los pueblos han sido mantenidos acerca de sus derechos habría hecho ver como un delito lo que en si era una virtud, y porque últimamente la abdicación de Carlos IV, la renuncia de su hijo Fernando en Bonaparte, su prisión y detención en Francia han roto y disuelto de una vez y para siempre los vínculos con que parecíamos estar ligados aunque injusta e ilegítimamente. $\mathrm{Y}$ en cuanto á lo segundo, porque decidida por la España la disolución del pacto social anterior, declarada la soberanía y reversión al pueblo como a quien solo corresponde, organizado un gobierno por el voto de sus representantes, y proclamada solemnemente la integridad de América en el todo de la monarquía, considerada como un pueblo entero constitutivo de la nación, ha sido vejada en la representación, oprimida en la manera de gobierno, insultada en sus reclamaciones, tratada como rebelde é insurgente, y convertida en un teatro sangriento de muerte y desolación.

P. Pues qué ¿nosotros somos vasallos de España?

R. No, ni nunca lo hemos sido.

P. ¿Y por qué los españoles vindican para sí este derecho?

R. Porque siempre han considerado a los americanos como hombres de otra especie inferiores a ellos, nacidos para obedecer y ser mandados como si fuésemos un rebaño de bestias.

P. ¿Y qué decimos a esto?

R. Que los Americanos son y han sido en todo tiempo hombres libres, 
iguales a los españoles, franceses, ingleses, romanos y cuantas naciones han y ha habido, o haber pueda en el mundo, y que por lo mismo ningún hombre ni nación alguna tiene el menor título a mandarnos, ni a exigir de nosotros obediencia sin nuestro expreso general consentimiento.

P. ¿Y si a pesar de carecer de todo motivo de justicia lo intenta con la fuerza, qué recurso nos queda?

R. Resistirles en cumplimiento de la ley natural que faculta a todo hombre para oponer la fuerza a la fuerza, con el interés de conservar la vida, la libertad y propiedad individual.

P. ¿Y en resistirles no se comete algún delito?

R. antes bien no resistiéndoles, porque el hombre no puede dejar a sus hijos y descendientes la servidumbre y opresión como acaecería dejándose subyugar pacíficamente.

P. ¿Pero la conquista de América no ha tenido trescientos años de posesión quieta y tranquila?

R. Bien podría decirse que esta posesión ha sido turbada por repetidas conmociones parciales, que desgraciadamente se han malogrado; pero aun cuando fuese, estos sirve de justificar más nuestra conducta actual.

P. ¿Por qué?

R. Porque trescientos años de cadenas, de oprobios, de insultos, de depredaciones, en una palabra, de todo género de padecimientos en silencio y paciencia no pueden servir de prescripción contra millones de hombres; y ellos no podía dejar de interesar, algún día, a la Providencia a nuestro favor, devolviéndonos el precioso derecho de existir libres de la tiranía, y brindándonos la oportunidad de sacudir tan pesada como ignominiosa coyunda.

P. ¿Luego la guerra que sostenemos es una guerra justa?

R. Sí, una guerra justa y santa, y acaso la más justa y santa que se ha visto en el mundo de muchos siglos acá.

P. Qué deberemos decir de la propagación de la Religión Cristiana ¿será esta un título justo de dependencia?

R. Es injurioso a la misma religión el pensar solo que ha sido publicada entre nosotros para subyugarnos.

P. Pero los españoles, ¿no recurren a su establecimiento en América para que les seamos dependientes?

R. Sí, pero solo por ignorancia y barbarie podrían consagrar semejante pretensión.

P. ¿Pues qué, no debemos a ellos el beneficio de ser cristianos?

R. Por casualidad les somos deudores de la publicación del Evangelio.

$\mathrm{P}$ ¿Por qué decís casualidad?

R. Porque Cristóbal Colón, que fue quien descubrió el nuevo mundo, y por cuya empresa logró reunir cuatro aventureros, tan lejos estuvo de pensar en 
Religión Católica, cuanto que su objeto principal era solo perfeccionar ciertos cálculos en el adelantamiento de su profesión, que era la náutica.

P. Y bien, los españoles que sucesivamente fueron empresarios como Colón, ¿no vinieron animado del celo de la religión?

R. Ninguno se propuso jamás este fin, pues que en lo general eran gentes ignorantes, hombres criminales detenidos en las cárceles criminales, la hez del pueblo.

P. ¿Pero qué era lo que les animaba a tantos riesgos y trabajos?

R. La sed insaciable de oro.

$\mathrm{P}$ ¿Y qué, no trajeron ministros y predicadores del Evangelio?

R. Vino uno u otro después de las primeras incursiones, pero tan codiciosos y hambrientos de riquezas como sus compañeros.

P. ¿Y predicaron estos el Evangelio?

R. Tal cual vez se aparentaron hacerlos fue contrariando enteramente todas las instituciones de su divino amor.

P. Explicadme ¿de qué modo?

R. Predicando un Evangelio que todo es paz y caridad con escoltas de soldados, que dejaban por lo común cubierto de cadáveres el lugar de la predicación, exigiendo por condición precisa y esencial al Evangelio; la subyugación a España, la destronación de los príncipes legítimos, é inmensas contribuciones.

P. Pero a pesar de todo esto ¿no lograron destruir la idolatría y dar a conocer al verdadero Dios?

R. Jesu - Cristo no ha querido que alguien sea forzado para abrazar la Religión. Sus primeros discípulos no tuvieron más armas para predicarla que la palabra y el convencimiento. Por este medio fue que convirtieron también a millares de habitantes de idolatras, a quienes, cuando resistieron abrazar el cristianismo, no se les opuso, por parte de los Apóstoles, ejércitos ni armadas, sino la paciencia, y el sufrimiento con que, arrostrando todo género de persecución, dieron últimamente testimonio a su misión con su propia sangre.

P. ¿Entonces, a quién somos deudores de la Religión?

R. Primaria y principalmente a la omnipotencia de Dios, que solo pudo vencer a los obstáculos que los mismos cristianos españoles oponían a su establecimiento y propagación, y después al celo de uno u otro varón verdaderamente apostólico, que más tuvieron que sufrir la parte de los mismos españoles que de la de los indios a quienes dócilmente convertían.

P. ¿Pues cómo es que los reyes han blasonado siempre de que a su celo y cuidado se ha debido la Religión Católica en estos países, que han edificado templos, erigido altares, dotado ministros, y esto todo a sus expensas?

R. Y ¿quién había de haberse atrevido a desmentirlos? Después que dejó de correr a grandes torrentes la sangre humana, cuando millones de víctimas 
sacrificadas a la insaciable codicia de los españoles convirtieron en desiertos espantosos las poblaciones más numerosas, cuando errantes las tribus que había perdonado la espada de los conquistadores no temieron ser inquietados en la posesión de presa tan rica, y lograron imponer el pesado yugo que acabamos de sacudir; en la calma, digo, de tantos asesinatos y atrocidades, la Religión Cristiana comenzó a establecerse, y se vieron tempos, sacerdotes y altares. Los indios, que desgraciadamente eran repartidos, o vendidos como esclavos a los mismos Conquistadores iban recibiendo esta misma Religión por ser la de sus amos a la manera que ha sucedido entre nosotros con los esclavos de la costa de África, de cuya adquisición jamás ha sido fin principal el cristianismo, sino el servicio de las haciendas \&c. Después de algún tiempo los pueblos que se iban formando tenían un sacerdote, que con el azote en la una mano y la cruz en la otra, les hacían aprender los misterios de nuestra creencia, y esto tan mal que puede decirse que en ellos no ha habido una verdadera educación religiosa. A más de esto, ¿cómo presumir siquiera que la publicación del Evangelio haya ocupado a los primeros tránsfugos de España en América, cuando solo ellos pudieron suscitar la injuriosa duda de pertenencia o no los indios á la raza humana, repuntándolos como incapaces de los Sacramentos de la Iglesia. Últimamente los fondos para el sostenimiento del culto, los templos, alteres, $\& c$. han sido erogaciones de los particulares, y en lo que se dice haberse hecho a costa del real erario, todo ha sido de nuestras contribuciones y pechos, del ignominioso tributo que los indios y de tanta sacaliña con que diversos nombre hemos sido gravados. ¿Qué dinero, qué alhaja qué cosa de provecho nos ha traído España? Antes bien los Reyes han importunado frecuentemente a la Silla apostólica para adquirirse las rentas de la Iglesia, ya exigiendo parte de los diezmos, ya apropiándose en las vacantes de los Obispados y prebendas, ya gravando estas, aquellos y las parroquias con medias antas, subsidios, anualidades, \&c.: de manera que el gabinete de Madrid parecía que tenía decretado un saqueo general a los bienes de la Iglesias sin reservar más que las indispensablemente precisas.

P. ¿Qué deberemos concluir de todo esto?

R. Que si amamos de veras a la Religión Católica, si deseamos conservarla, vivir y morir en ella, son de redoblarse nuestros esfuerzos para no volver jamás a la dependencia antigua.

P. La Religión Católica desconoce la distinción de pueblos y de gobiernos. En Asia y en la África, en la Europa y en la América, en las monarquías y en las Repúblicas en los gobiernos libres y hasta en los despóticos se acomoda perfectamente el Cristianismo. Los españoles bien satisfechos de nuestra íntima adhesión a él han tratado de hacernos la guerra por este medio. Ellos han encontrado algunos ministros, que, prostituyendo el carácter augusto de la divina misión han turbado la paz interior de algunos espíritus tímidos y 
apocados, imbuyéndoles máximas contrarias a la una religión que no conoce ni la esclavitud ni las cadenas, y que debe reportar grandes ventajas a con nuestra emancipación y libertad.

P. ¿Qué ventajas son estas?

R. $1^{\circ}$. La del estudio y conocimiento de la misma religión: el Gobierno que deber protegerla como la exclusiva Religión del Estado dirigirá sus primeras atenciones hacia el importante objeto de la educación Cristiana de los pueblos. Es sumamente doloroso ver la ignorancia que hasta aquí hemos vivido respecto a ella. Un mal Catecismo en que, con las menos palabras posibles se duplican los principales misterios de nuestra creencia; una multitud de librejos que, con el título de vida y milagros de este o aquel santo, servía para darnos las primeras lecciones en la escuela como para acostumbrarnos desde la infancia a creer patrañas y falsos milagros, a ser fanáticos y supersticiosos: maestros que educados de la misma suerte jamás podrían forman sino discípulos peores que ellos: colegios y universidad en que se embotaba el talento de la juventud con los embrollos y sutilezas del escolasticismo, y que, con el nombre de Teología, todo se enseñaba menos las prueba su fundamentos de la Religión Cristiana; todo esto entrará en el plan de una reforma capaz de hacernos cristianos por principios, y de consiguiente librarnos de los falsos temores de peligro en la religión por nuestra comunicación con los que no la profesan. 2. Tendremos entre nosotros mismos Pastores aptos y capaces de dirigir y gobernar las almas, sin aventurar ni exponernos a la contingencia de los que nos enviaban de España, acaso sin la suficiencia necesaria y sin el amor y caridad que debe distinguir las altas funciones del ministerio apostólico, trocadas algunas vez en odios y animosidades escandalosas. Por último establecidas nuestras relaciones con la Santa Sede obtendremos las gracias y privilegios que exijan nuestras espirituales necesidades, sin más consideración ni otro mérito que el de hijos de la Católica Iglesia. 